\title{
From TATA to single port robotic (SPr) taTME: approaches to distal rectal cancer
}

\author{
Emily Kunkel, Samir Agarwal, Charles Martin, Henry Schoonyoung, John H Marks \\ Department of Colon and Rectal Surgery, Lankenau Medical Center, Wynnewood, PA 19096, USA.
}

Correspondence to: Dr. Emily Kunkel, Department of Colon and Rectal Surgery, Lankenau Medical Center, Wynnewood, PA 19096, USA.E-mail: kunkel2@mlhs.org

\begin{abstract}
How to cite this article: Kunkel E, Agarwal S, Martin C, Schoonyoung H, Marks JH. From TATA to single port robotic (SPr)
\end{abstract} taTME: approaches to distal rectal cancer. Mini-invasive Surg 2020;4:27. http://dx.doi.org/10.20517/2574-1225.2020.05

Received: 9 Jan 2020 First Decision: 18 Feb 2020 Revised: 4 Mar 2020 Accepted: 9 Mar 2020 Published: 16 May 2020

Science Editor: Giulio Belli Copy Editor: Jing-Wen Zhang Production Editor: Tian Zhang

\begin{abstract}
The surgical management of rectal cancers located in the distal rectum presents a unique challenge for surgeons as it is anatomically unfavorable and technically difficult to access. Over the course of the 20th century, novel techniques contributed to the improvement of rectal cancer management and led to improved quality of life for patients following surgical resection. In this article, we explore the background of rectal surgery techniques, which have progressed from abdominal perineal resection to transanal abdominal transanal proctosigmoidectomy, transanal total mesorectal excision (taTME), and ultimately minimally invasive transanal sphincter preserving techniques utilizing single port robotic technology (SPr taTME). In the first clinical experience with the DaVinci SP robot in the United States, we are finding many advantages of this new platform in transanal surgery. The SP offers superior image quality with 3D view, wristed instruments facilitating ergonomics, and superior surgical precision.
\end{abstract}

Keywords: Transanal abdominal transanal, transanal minimally invasive surgery, da Vinci single-port robot, transanal, rectal cancer

\section{INTRODUCTION}

"An invention has to make sense in the world it finishes in, not in the world it started." Tim O'Reilly.

For a large portion of the 20th century, low-lying rectal cancers were commonly treated by performing an abdominoperineal resection (APR), first reported by Miles ${ }^{[1]}$ in 1908 [Figure 1]. While the APR is oncologically effective, it distinctly alters the gastrointestinal anatomy and leaves the patient with a permanent colostomy. This procedure was adopted as standard treatment for rectal cancer for much of the

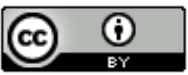

(c) The Author(s) 2020. Open Access This article is licensed under a Creative Commons Attribution 4.0 International License (https://creativecommons.org/licenses/by/4.0/), which permits unrestricted use, sharing, adaptation, distribution and reproduction in any medium or format, for any purpose, even commercially, as long as you give appropriate credit to the original author(s) and the source, provide a link to the Creative Commons license, and indicate if changes were made.

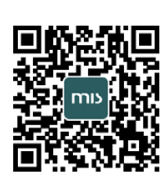




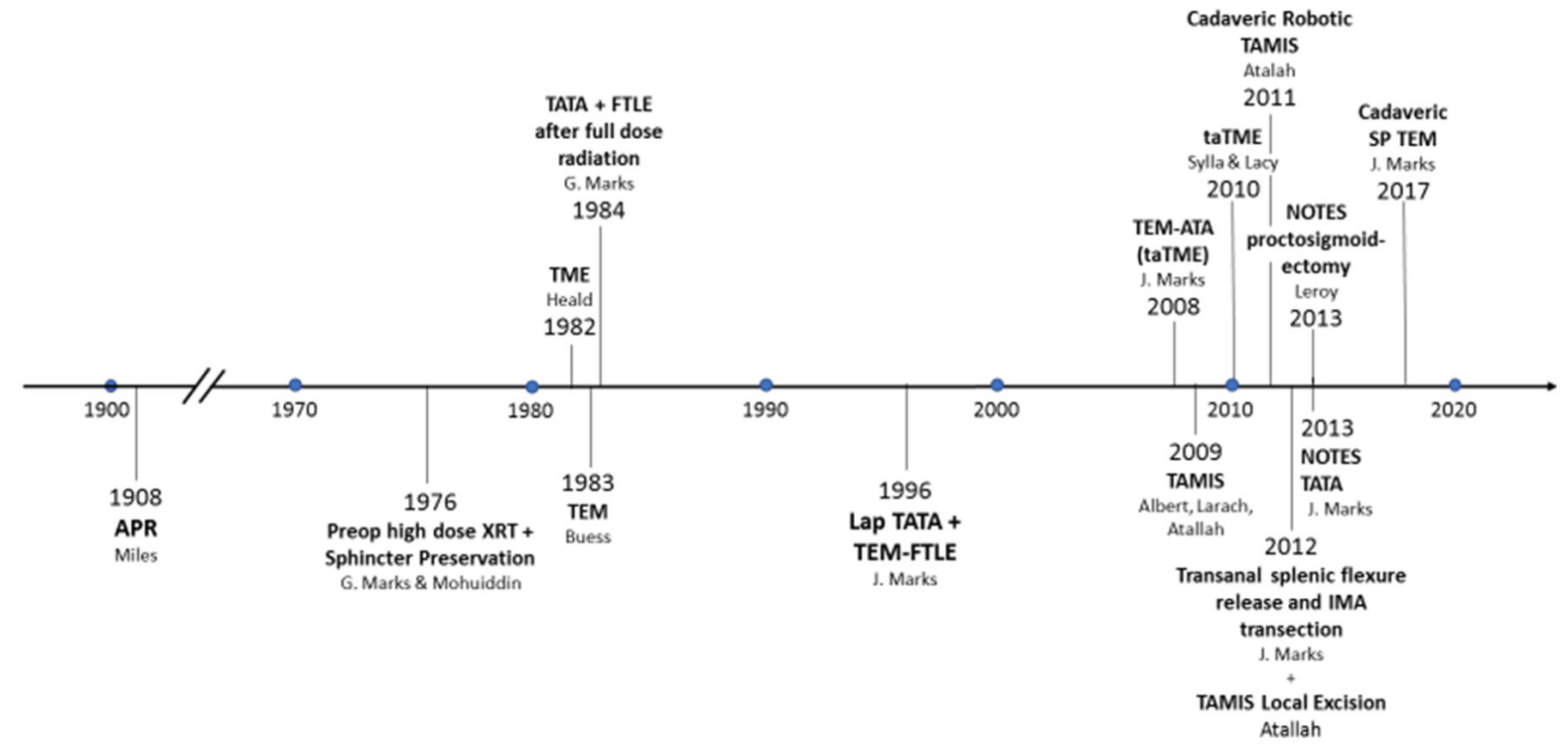

Figure 1. Timeline depicting of the evolution of rectal cancer. APR: abdominoperineal resection; TEM: transanal endoscopic microsurgical; TME: total mesorectal excision; TATA: transanal abdominal transanal; FTLE: full thickness local excision; SP: single port; NOTES: natural orifice transluminal endoscopic surgery; TAMIS: transanal minimally invasive surgery; taTME: transanal total mesorectal excision; XRT: radiation; ATA: abdominal transanal; IMA: inferior mesenteric artery

century. However, local recurrence (LR) rates of $20 \%-40 \%$ in the 1970 s and 1980 s and a desire to extend sphincter preservation led to critical advances in rectal cancer management ${ }^{[2]}$.

Improved operative approaches and high dose preoperative radiation were shown to reduce the rates of LR in rectal cancers over the latter half of the 20th century ${ }^{[3]}$. In 1982, Heald and Ryall ${ }^{[4]}$ sharpened the focus on precision and proper surgical technique by performing meticulous dissection of the mesorectum and formulating the term total mesorectal excision (TME). TME has since become a fundamental principle in rectal cancer surgery and proved to reduce local recurrence rates.

Prior to this, in 1976, Mohiuddin et al. ${ }^{[5]}$ embarked upon the first program in the world that offered sphincter preservation following high dose radiation therapy in the preoperative setting. It was quickly realized that the irradiated rectal cancer was often so downstaged that sphincter preservation could be expanded. A challenge existed in the diminished size, making the tumor difficult to reliably palpate intraoperatively, hence leading to difficult determination of the distal tumor margin. To address these two problems of extending sphincter preservation and assuring an adequate distal margin, a new operative technique was conceived. In 1984, Marks et al. ${ }^{[6]}$ developed the transanal abdominal transanal (TATA) proctosigmoidectomy with coloanal anastomosis. The operation commences by incising the rectum in a full thickness fashion at the level of the dentate line and continuing the dissection cephalad. The rectal lumen is oversewn in a watertight fashion. In this manner, a known distal margin to the tumor is established and a total proctosigmoidectomy is then accomplished from an abdominal approach. This resection is followed by a direct coloanal anastomosis using healthy, non-radiated tissue from the descending colon, and avoids the need for a permanent colostomy. Contrary to the standard treatment of cancers in the distal third of the rectum, which requires navigation through the narrow confines of the deep pelvis, the TATA procedure avoids the need to apply a stapler from above. An underemphasized benefit of this approach is that the most difficult part of the operation is carried out transanally, at the beginning of the operation. In addition to preserving sphincter function, Marks et al. ${ }^{[7]}$ was able to reduce the local recurrence rate to $9 \%$ in a time where local recurrence was reported to be $25 \%$. The TATA procedure was shown to provide an oncologically safe sphincter preserving procedure for patients that otherwise would have received an $\mathrm{APR}^{[7]}$. 

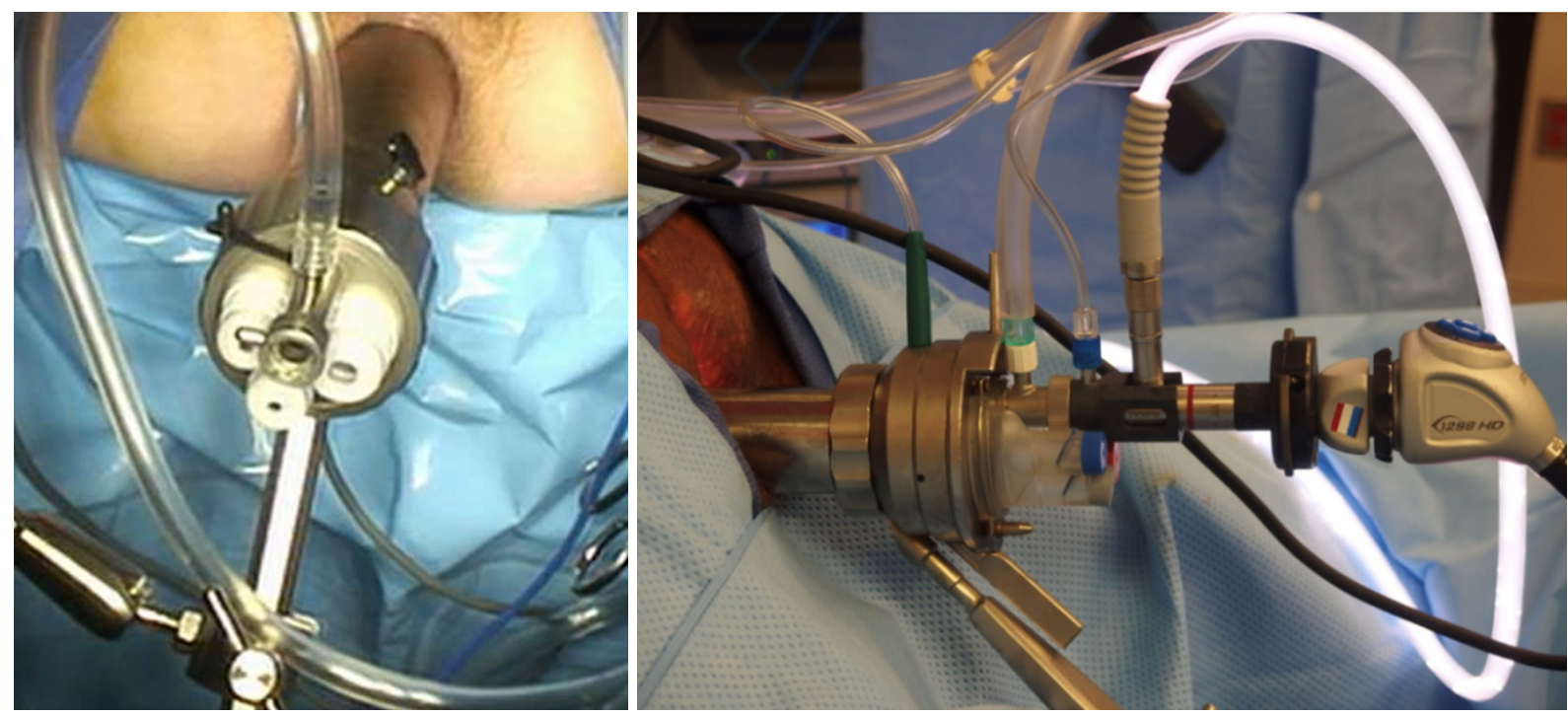

Figure 2. Transanal endoscopic microsurgical platform inserted transanally

In 1984, following the conception of the TATA, Kosinski et al. ${ }^{[8]}$ ventured to perform a full thickness local excision (FTLE) of a distal rectal cancer after full-dose radiation. This early experience demonstrated that local excision after neoadjuvant radiation could not only be performed successfully, but also safely with a low rate of local recurrence. This approach was slowly adopted due to the engrained beliefs that operating in an irradiated field leads to poor healing and high leak rates. However, due to superior oncological outcomes, the advantages of multimodal therapy were ultimately accepted, and neoadjuvant therapy became a standard practice in locally advanced cancers.

As is often the case with emerging technologies, the advent of minimally invasive surgery brought about further advancement in the surgical treatment of rectal cancer. Prior to the first laparoscopic abdominal procedure, in 1983, Dr. Buess ${ }^{[9]}$ developed the transanal endoscopic microsurgical (TEM) platform for resection of rectal polyps and early stage cancer [Figure 2] ${ }^{[10]}$. This technique used rigid laparoscopic instruments via a single transanal port to provide superior reach and exposure to rectal pathology that limited prior open transanal approaches. Dr. John Marks furthered this technique in 1996 when he performed a transanal endoscopic microsurgery full thickness local excision (TEM-FTLE) following neoadjuvant high-dose radiation. Later, in 2008, he used the TEM platform to perform the first transanal total mesorectal excision, which he termed TEM-ATA.

TEM was the first example of natural orifice transluminal endoscopic surgery (NOTES), which led to many advancements in minimally invasive surgery and specifically rectal surgery. In 2009, Atallah et al. ${ }^{[11]}$ developed the transanal minimally invasive surgery (TAMIS) platform [Figure 3]. While similar to the TEM technique, TAMIS allowed surgeons to perform radical rectal excisions via a more accessible single incision port as opposed to the rigid TEM proctoscope. Lacy et al ${ }^{[12]}$ further facilitated transanal access to rectal pathology by conducting an IRB-approved study of the single incision laparoscopic surgery platform. They are to be credited with popularizing transanal total mesorectal excision (taTME).

Both Drs. John Marks and Joel Leroy can be recognized for pushing the limits of transanal surgery using the TAMIS technique. In 2012, Dr. Marks accomplished the first transanal splenic flexure release and IMA transection. In 2013, Leroy et al. ${ }^{[13]}$ performed the first "pure" NOTES proctosigmoidectomy, which he termed peri-rectal oncologic gateway for retroperitoneal endoscopic single site surgery. In the same year, the first NOTES TATA was demonstrated by Marks et al. ${ }^{[14]}$, who later published a dynamic manuscript 


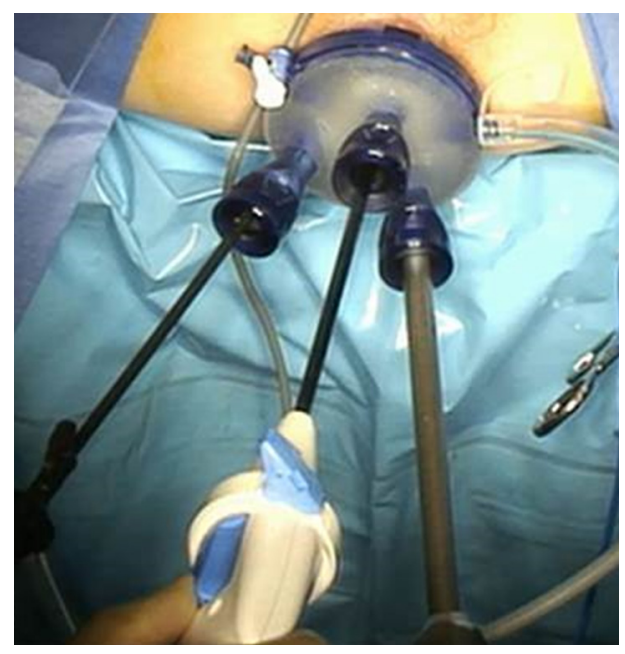

Figure 3. Transanal minimally invasive surgery platform inserted transanally

outlining the critical views for pure NOTES proctosigmoidectomy via TAMIS. While these advancements highlight what can be achieved transanally by highly experienced surgeons with single port laparoscopy, the ergonomics and technical challenges of these approaches resulted in limited adoption of these techniques.

As robotic surgery emerged, Atallah et al. ${ }^{[15,16]}$ described the first robotic TAMIS in 2011 using the da Vinci Si robot on a cadaveric model and later performed the first local excision of rectal cancer on a live patient in 2012. Subsequent to this, several institutions have reported on their experience with robotic TAMIS. The advantages reported are superior 3D view, wristed instruments, better ergonomics, and superior precision. Despite these benefits, the multi-arm robot was found to be ill-suited for single port surgery. External arm clashes and internal conflicts have relegated this approach to an interesting novelty.

With the clinical introduction of the da Vinci Single Port (SP) robot, many of these hurdles of robotic single port surgery have been addressed, employing this technology in the next generation of robotic TAMIS (rTAMIS). The da Vinci SP platform is a single arm single port system that is ideal for rectal procedures [Figure 4]. The SP system includes three 6- $\mathrm{mm}$ jointed and wristed instruments and the first da Vinci jointed $3 \mathrm{D}$ camera [Figures 5 and 6]. This facilitates viewing and operating on all quadrants of the rectum without repositioning the patient. The hologram of instrument position seen on the SP screen allows the surgeon to better avoid instrument collision and permits superior retraction. Current instruments available for the SP robotic system include: needle driver, cadiere forceps, round tooth retractor, clip applier, monopolar scissors, monopolar hook and spatula tip cautery, and both Maryland and fenestrated bipolar forceps. To date, there is no SP vessel sealer, suction, or stapler. These represent significant drawbacks that will likely be addended in the near future.

In a cadaveric feasibility study, the SP robot was shown to be a realistic platform for the future of endoluminal surgery. As reported in a manuscript published in 2017, Marks et al. ${ }^{[17]}$ performed 12 local excision procedures (SPr TAMIS) with no fragmentation of the specimen and negative margins. In January 2020, the first clinical experience performing a single-port left colectomy using the SP robot (SPr SILS left colectomy) was described ${ }^{[18]}$. Relative ease and comfort were noted with this novel operative platform with minimal physical or mental fatigue to the surgeon. In an FDA regulated feasibility study, the use of the SP robot was expanded to perform transanal TME dissections. Building on prior laparoscopic transanal total mesorectal excision experiences, Dr. Marks began utilizing the SP robot in total transanal TME procedures, including transanal splenic flexure release and high ligation of the IMA. The results of these experiences have yet to be published. With these advances, the SP robot demonstrates significant surgical milestones 


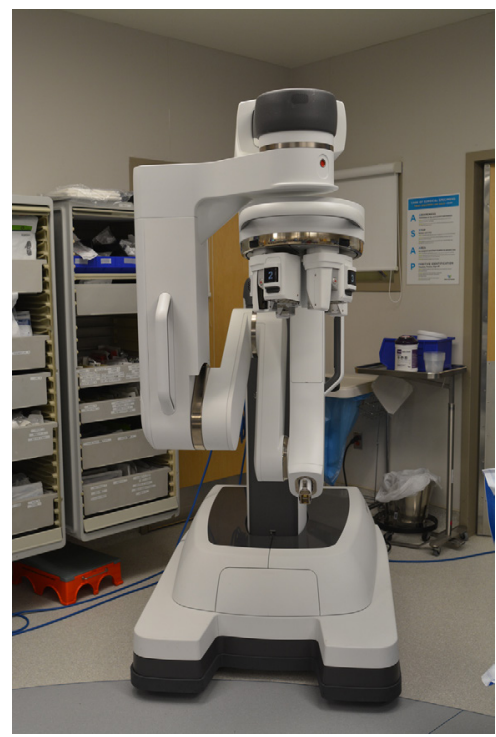

Figure 4. Single port robotic platform

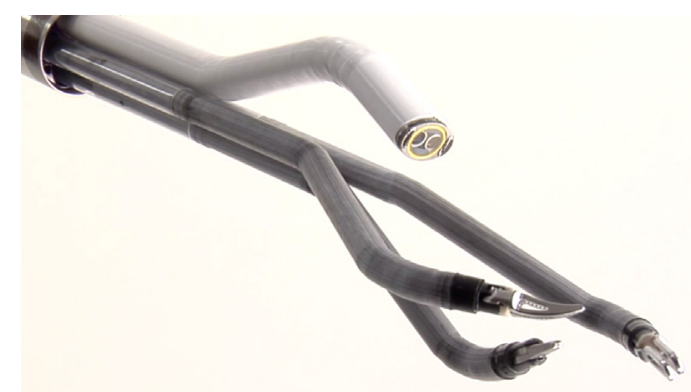

Figure 5. Angulation of single port robotic instruments employed through the single port trocar

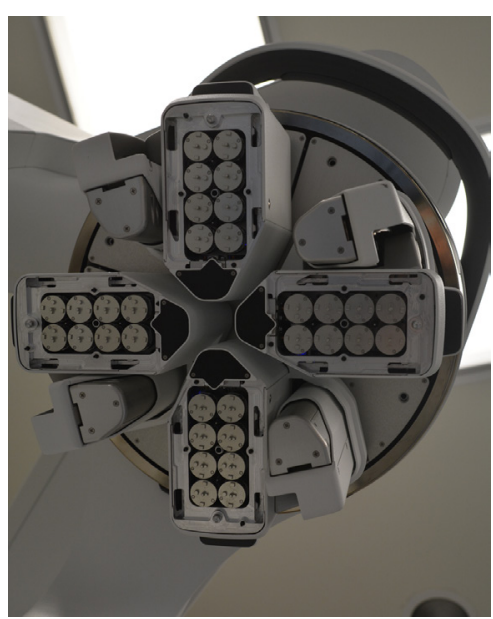

Figure 6. Single port instrument insertion platform

in the field of transanal and other natural orifice surgery. From APR, to TEM and NOTES, to TAMIS and the advent of SP robotic transanal surgery, technological advances are constantly providing surgical and oncological advantages in the treatment of rectal cancer. 


\section{DECLARATIONS}

\section{Authors' contributions}

Made substantial contributions to conception and design of the study: Kunkel E, Martin C, Agarwal S, Marks JH

\section{Availability of data and materials}

Not applicable.

\section{Financial support and sponsorship}

None.

\section{Conflicts of interest}

E Kunkel, C Martin, S Agarwal and H Schoonyoung have no conflicts of interest to disclose. Dr. John Marks is engaged with Intuitive Surgical in a consultative fashion to develop the safe application of the SP robot. This has entailed detailed conversation as well as cadaver work utilizing a robotic protocol. He has been financially compensated for this work.

\section{Ethical approval and consent to participate}

Not applicable.

\section{Consent for publication}

Not applicable.

\section{Copyright}

(C) The Author(s) 2020.

\section{REFERENCES}

1. Miles WE. A method of performing abdomino-perineal excision for carcinoma of the rectum and of the terminal portion of the pelvic colon (1908). CA Cancer J Clin 1971;21:361-4.

2. Olson RM, Perencevich NP, Malcolm AW, Chaffey JT, Wilson RE. Patterns of recurrence following curative resection of adenocarcinoma of the colon and rectum. Cancer 1980;45:2969-74.

3. Mohiuddin M, Marks GJ. High dose preoperative radiation and sphincter preservation in the treatment of rectal cancer. Int $J$ Radiat Oncol Biol Phys 1987;13:839-42.

4. Heald RJ, Ryall RD. Recurrence and survival after total mesorectal excision for rectal cancer. Lancet 1986;1:1479-82.

5. Mohiuddin M, Dobelbower RR, Turalba C, Kramer S, Marks G. A selective sandwich technique of adjuvant radiotherapy in the treatment of rectal cancer: a preliminary experience. Dis Colon Rectum 1979;22:1-4.

6. Marks G, Bannon JP, Marks J. Transanal-abdominal transanal radical proctosigmoidectomy with coloanal anastomosis for distal rectal cancer. In: Nyhus L, Baker R, Fischer J, editors. Mastery of Surgery, 3rd ed. Little, Brown and Company, Boston, MA; 1996.

7. Marks GJ, Marks JH, Mohiuddin M, Brady L. Radical sphincter preservation surgery with coloanal anastomosis following high-dose external irradiation for the very low lying rectal cancer. Recent Results Cancer Res 1998;146:161-74.

8. Kosinski LA, Marks JH, Marks GJ. Full-thickness local excision. In: Cataldo PA, Buess GF, editors. Transanal endoscopic microsurgery. Springer: Verlag New York; 2009. pp. 109-15.

9. Litynski GS. Profiles in laparoscopy: mouret, dubois, and perissat: the laparoscopic breakthrough in Europe (1987-1988). JSLS 1999;3:163-7.

10. Perissat J. Laparoscopic cholecystectomy: the European experience. Am J Surg 1993;165:444-9.

11. Atallah S, Albert M, Larach S. Transanal minimally invasive surgery: a giant leap forward. Surg Endosc 2010;24:2200-5.

12. Lacy AM, Adelsdorfer C, Delgado S, Sylla P, Rattner DW. Minilaparoscopy-assisted transrectal low anterior resection (LAR): a preliminary study. Surg Endosc 2013;27:339-46.

13. Leroy J, Barry BD, Melani A, Mutter D, Marescaux J. No-scar transanal total mesorectal excision: the last step to pure NOTES for colorectal surgery. JAMA Surg 2013;148:226-30.

14. Marks JH, Lopez-Acevedo N, Krishnan B, Johnson MN, Montenegro GA, et al. True NOTES TME resection with splenic flexure release, high ligation of IMA, and side-to-end hand-sewn coloanal anastomosis. Surg Endosc 2016;30:4626-31.

15. Atallah S, Parra-Davila E, DeBeche-Adams T, Albert M, Larach S. Excision of a rectal neoplasm using robotic transanal surgery (RTS): a description of the technique. Tech Coloproctol 2012;16:389-92.

16. Atallah SB, Albert MR, deBeche-Adams TH, Larach SW. Robotic transanal minimally invasive surgery in a cadaveric model. Tech 
Coloproctol 2011;15:461-4.

17. Marks J, Ng S, Mak T. Robotic transanal surgery (RTAS) with utilization of a next-generation single-port system: a cadaveric feasibility study. Tech Coloproctol 2017;21:541-5.

18. Marks JH, Salem JF, Anderson BK, Josse JM, Schoonyoung HP. Single-port left colectomy: first clinical experience using the SP robot (rSILS). Tech Coloproctol 2020;24:57-63. 